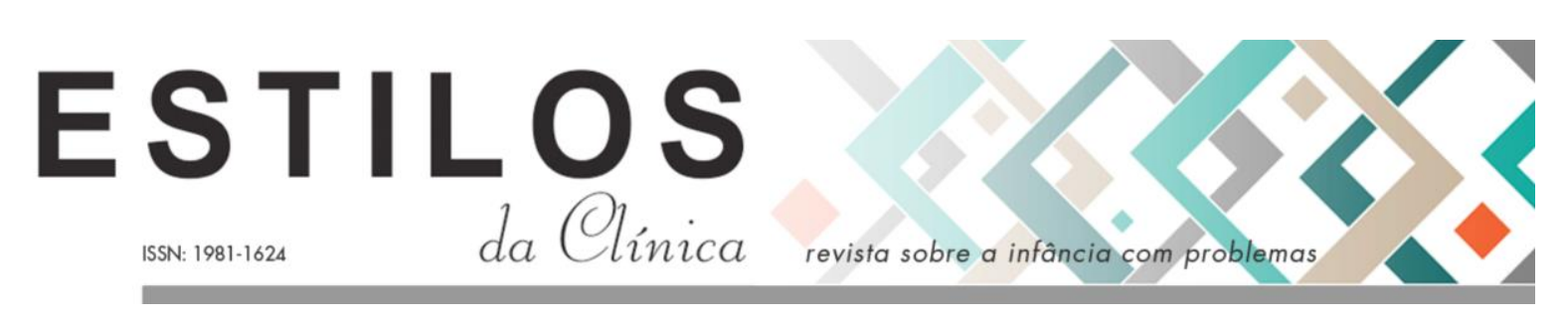

DOI: https://doi.org/10.11606/issn.1981-1624.v24i3p432-444.

\title{
Artigo
}

\section{A função materna e seu lugar na constituição subjetiva da criança}

\author{
Maria Gláucia Pires Calzavara; Monique Aparecida Vale Ferreira
}

\begin{abstract}
Resumo. Partimos do dito mãe geladeira, que se apresenta na mídia especulativa como um representante da práxis psicanalítica, sobretudo na clínica das patologias infantis, e buscamos elucidar essa expressão como um equívoco necessitando de elaboração. Para tal, seguiremos pelos autores pós-freudianos, que se amparavam na maternagem para dizer do sujeito, posição que pode ter contribuído para esse equívoco, e nos dirigimos a Lacan, que elucida e diferencia o lugar da mãe mulher como uma função. Enfim, concluímos que esse dito, na atualidade, se revela como mais uma forma de ataque à psicanálise no que se refere ao tratamento das crianças autistas.
\end{abstract}

Palavras chave: psicanálise; criança; função materna.

\section{La función materna y su lugar en la constitución subjetiva del niño}

Resumen. Partimos del clásico comentario de la "madre fría" como supuestamente representante de la praxis psicoanalítica, sobre todo en la clínica de las patologías infantiles, y buscamos elucidar esa expresión como un siendo equívoco que merece ser analizado. Para eso, seguiremos los autores post-freudianos que, apoyándose en el maternaje para decir del sujeto, contribuyeran con ese equívoco, posteriormente nos ocupamos de Lacan, que elucida y diferencia el lugar de la madre mujer como una función. Concluimos que esa idea de la "madre fría" revelase como una forma más de ataque al psicoanálisis en lo que se refiere al tratamiento de los niños autistas.

Palabras clave: psicoanálisis, niño, función materna.

\section{The maternal function and its place in the child's subjective constitution}

Abstract. We start from the maxim refrigerator mother, which presents itself in the speculative media as a representative of the psychoanalytical practice, especially in the clinical of childhood pathologies, and we seek to elucidate this expression as a mistake requiring elaboration. For that, we will follow the post-Freudian authors, who took refuge in the maternity to say of the subject, a position that may have contributed to this misconception, and we address to Lacan, who elucidates and differentiates the place of the mother woman as a function. Finally, we conclude that this saying, nowadays, reveals itself as another form of attack on psychoanalysis with regard to the treatment of autistic children.

Keywords: psychoanalysis, child, maternal function

*Professora Adjunta do Departamento de Psicologia da Universidade Federal de São João Del- Rei, São João Del Rei, MG. Email: glauciacalzavara@gmail.com

**Graduada em Psicologia pela Universidade Federal de São João Del Rei, São João Del Rei, MG. Email: moniqueferreira08@gmail.com 


\section{"Vão te chamar de mãe geladeira!"}

Esta é uma expressão proferida pelo pai - profissional da abordagem comportamental - de uma criança autista diante da afirmativa da mãe dessa criança, que aceitaria ter seu filho atendido pela abordagem psicanalítica. Não nos causou estranheza tal comentário, uma vez que essa expressão ressoa na clínica com crianças autistas no que concerne à relação entre estas e suas mães, essencialmente a respeito da práxis psicanalítica. Reconhecemos essa expressão como um equívoco, necessitando de elaboração tanto para os familiares quanto para aqueles que desconhecem o que é da ordem do materno para a psicanálise. Frente a isso, partiremos desse equívoco, que, também, toma os espaços da mídia especulativa e reducionista no que concerne ao dito - "mãe geladeira" - como representante contumaz, na palavra dos leigos, da práxis psicanalítica, sobretudo na clínica de crianças autistas.

Na década de 1940, Leo Kanner, psiquiatra e estudioso das primeiras descrições sobre a causalidade do autismo, já nos chamava atenção sobre a influência da própria família na gênese do autismo utilizando-se do dito referido anteriormente. Amparado em um momento histórico e social, em que o quadro clínico do transtorno autista se travestia de esquizofrenia, tal como estudado e entendido por Joseph Bleuer, Kanner (1943/1997), além disso, convocava um olhar para a relação mãe e fillho como possível delineadora dessa patologia. Possível é como denominamos na atualidade essa posição, aludida no passado, para demonstrar que a redução desse referido dito "mãe geladeira", por parte de alguns especialistas, os quais sustentam outras abordagens que não a psicanálise, e do mesmo modo aos leigos, se ampara em um grande equívoco que necessita de uma elucidação.

Comungando ainda desses ideais, o psicanalista Bruno Bettelheim (1967/1987) ao publicar seu livro "Fortaleza Vazia", enfatizou ainda mais o autismo como fruto do laço conflituoso estabelecido entre mãe e filho, tornando popular o dito "mãe geladeira" tanto no meio acadêmico quanto no meio social, que abriga, também, leigos.

A função materna, como protagonista na constituição psíquica dos sujeitos, teve, ao longo do tempo, inúmeras passagens de entendimentos e equívocos. Como primeiro objeto de amor e agente dos primeiros cuidados na relação com o filho, a mulher mãe passou de uma posição santificada para a de devastadora. Essa relação, vivida como promotora de muitos impasses e convergências, nos leva a buscar esclarecer tal função materna para além de um lugar social, isto é esclarecê-la por meio de um lugar representativo de um desejo, o que, sobremaneira, se revela como iluminador dessa posição. Tal posição materna se apresenta como ponto de ancoragem na constituição do sujeito. No entanto, nosso objetivo quer revelar os equívocos no que se refere a essa nomeação para o sujeito autista. Isso porque os impasses do sujeito autista em sua constituição psíquica nos levam a elucidar a função materna para esse sujeito, que, por muito tempo, foi associada e "culpabilizada" por uma posição, que, de forma equivocada, instituiu-se no imaginário científico e social.

A partir de suas observações clínicas, Kanner (1943/1997) considerou o autismo como uma afecção psicogênica, cuja característica principal, que se dava desde o nascimento, era uma incapacidade da criança de estabelecer contato com seu meio. Esse era um ponto de distinção importante entre a esquizofrenia e o autismo.

O fato é que, em suas primeiras elaborações sobre o autismo, Leo Kanner (1943/1997) apresentava de forma contundente suas observações sobre a relação entre a figura materna e a criança autista. Tal recorrência em observar e destacar sobre essa relação inicial entre mãe e 
filho trouxeram-lhe implicações no campo teórico, essencialmente no que se refere ao laço entre mãe e filho. Desse modo, suas questões se amparavam no questionamento se, porventura, o autismo teria uma etiologia genética ou se seria proveniente da relação conflituosa que a mãe tinha com seu filho. Como características principais dessa relação materna, já observadas por Kanner (1943/1997), destacam-se a frieza, a apatia e certa dificuldade de estreitar os laços com a criança. Além do mais, tal relação se destacava quando os pais apresentavam um alto nível intelectual - quando a razão prevalece à emoção. Esses atributos que caracterizavam a mãe, diz-nos Kupfer (2000), poderiam interferir na dificuldade dessas crianças em se relacionar afetivamente com os outros. Essa foi uma teoria que imprimiu nas patologias infantis uma marca que destacava a mãe como um personagem substancialmente responsável pelo percurso subjetivo da criança.

Sem se afastar de suas considerações clínicas, Leo Kanner (1943/1997), como pioneiro na exposição do autismo, incidiu suas primeiras descrições sobre sua causalidade na relação da mãe com o filho. Conforme aponta Lopes (2017), um ponto de divergência essencial entre Kanner e Bettelheim diz respeito à própria etiologia do autismo. Enquanto Kanner abandona essas descrições, seguindo outro percurso no que concerne à etiologia orgânica do autismo, Bettelheim segue com a ideia de que o autismo se referia a uma patologia ancorada na psicogênese de modo que seu cerne estava no ambiente familiar adoecido, principalmente nas mães (Lopes, 2017).

Sendo assim, é interessante deslindarmos esta relação original e natural entre um ser vivente e aquele que o ampara, visto que foi precursora de teorias que se pautavam na maternagem como organizadoras da função do eu do sujeito. Percorrer o caminho desses pioneiros no estudo da relação da criança com a mãe será relevante para o entendimento desse equívoco, bem como a posição da mãe ao longo desse percurso.

\section{Teóricos da relação mãe e filho}

Os teóricos infantis que trabalhavam as patologias clínicas amparados na dificuldade da relação primeira entre mãe e filho ampliavam, a partir daí os enganos sobre a causalidade das patologias infantis.

No que concerne à orientação clínica, Kanner (1943/1997) se amparou em um primeiro momento na vertente psicanalítica de Margaret Mahler, na relação mãe e fillho. Mahler, pediatra e psicanalista húngara, iniciou seus estudos sobre o autismo e psicose a partir de 1949. Conforme Barroso (2014), Mahler foi a primeira psicanalista a elaborar uma teoria sobre o autismo. Ela acolheu uma versão da psicanálise do ego com a psicologia genética de Piaget para explicar o autismo. Mahler, continua Barroso (2014), acreditava que a criança passa por três etapas para sua constituição psicológica: 1- fase de um autismo normal primário; 2- fase simbiótica, anterior à formação do eu corporal; e 3- fase de separação-individuação, na qual ocorre a distinção do eu e do não eu. A mãe, segundo Mahler, funciona como um eu auxiliar da criança e tem a função de permitir a individuação-separação. A separação, conforme Mahler, corresponde à posição de se sentir separada da mãe, fora da fusão com ela. Como uma dificuldade de lidar com a separação, "a psicose infantil autística seria uma fixação ou regressão à fase de autismo normal, e a psicose simbiótica, uma deformação do estágio normal de simbiose" (Barroso, 2014, p. 58). A teoria da psicose infantil de Mahler, a exemplo de algumas 
teorias sobre o autismo, pautou-se na função da maternagem como organizador da posição do eu.

Prosseguindo com Kanner (1943/1997), inicialmente, ele não se absteve, também, de uma perspectiva que considerava a etiologia do autismo ancorada na interação da criança com o seu meio, em que, consequentemente, estariam incluídas algumas condutas e comportamentos dos pais em relação aos seus filhos autistas. Contudo, ele permaneceu se associando às teses que se amparavam na causalidade orgânica do autismo e condescendendo, ao final, com o organicismo como explicação do autismo infantil, afastando-se, a partir de então, da investigação psicanalítica (Ribeiro, 2013). A teoria da "mãe geladeira" parece se revelar dessas ideias que ora privilegiavam a etiologia do autismo pela via da interação ambiental, ora pela via do organicismo.

Nos anos de 1950, a psicanalista inglesa Frances Tustin (1972/1975) ficou conhecida por seu trabalho com crianças autistas amparada na abordagem Kleiniana. A tese de Tustin (1972/1975) parte da ideia de que a criança, para se proteger de sua fragilidade, constrói, de forma ilusória, uma concha protetora como um invólucro externo ao corpo. Tustin critica, de maneira contundente, a teoria de Kanner sobre a frieza materna defendendo que esta pode estar sofrendo de depressão, o que a leva a ter dificuldades na relação com o filho (Ribeiro, 2013). Ou seja, podemos observar que, na concepção de Tustin, não há uma intenção materna de se isolar do filho, mas há circunstâncias adversas que podem possibilitar o afastamento. Desse modo, a defesa dos atributos maternos, que são estranhos e indiferentes ao filho, causou impasse na investigação de Kanner e não trouxe elaborações mais precisas sobre essa questão. Por outro lado, esse posicionamento dificultou o entendimento dado à importância da função materna como o que é por excelência submetido à ordem da linguagem.

Com os pós-freudianos, notamos que a proposição sobre a maternidade se ancora sobre a via da maternagem tal como Malher. Dessa forma, é preciso evocarmos Winnicott (1971/1975, p. 24) e o seu conceito de "mãe suficientemente boa", o qual aborda, não necessariamente, a figura da mãe biológica, mas sim de alguém que cumpra com a função de adaptação, quase que de modo integral, às necessidades do bebê. Todavia, com o passar do tempo, a devoção materna plena, isto é, a adaptação referida anteriormente, se reduz, paulatinamente, em função da capacidade do bebê em lidar com a frustração.

Segundo Lobo (2008), o destaque postulado por Winnicott sobre a maternagem e sua fundamental importância não tem uma finalidade pedagógica apoiada numa perspectiva de ensinar as mães como estas devem se comportar diante de seus filhos. Trata-se, na verdade, de um resultado de suas observações concernentes à prática pediátrica e, posteriormente, aos estudos psicanalíticos. Em suma, Lobo (2008) sugere que, talvez, a necessidade de Winnicott em endereçar-se às mães seria para preservá-las de uma maternagem, que poderia ser ora atemorizada, ora culpabilizada pela pediatria e até mesmo pela própria psicanálise.

Dessa maneira, compreender em qual posição se encontra a mãe do sujeito - seja ele autista, psicótico ou neurótico grave na relação subjetiva que ela tem com seu filho - e de que forma essa relação pode ser relevante e influenciar na subjetividade dessa criança são questões norteadoras, cuja investigação se torna imprescindível. 


\section{Constituição do sujeito}

Importante ressaltarmos que o sujeito da psicanálise é o sujeito do inconsciente. É um sujeito de desejo, sustentado por uma falta primordial que o movimenta e o faz humano. É, portanto, distinto do sujeito biológico, puro organismo. Ao falarmos de sujeito em psicanálise, entramos no campo da linguagem, da estrutura, do significante. É isso, dizem-nos Lefort \& Lefort (1983/1988/1991), que faz a unidade da psicanálise. É preciso, portanto, nos distanciarmos de uma abordagem personalista em que a família e as figuras que a representam tomam a cena, como, por exemplo: "Pai em casa, pai omisso, pai assustador. Não é a isso que se refere nos tratamentos, mas ao Nome do Pai, à estrutura, e também à topologia, pedra angular da transmissão da psicanálise" (Lefort \& Lefort, 1983/1988/1991, p. 11). Desse modo, o que do sujeito se estrutura se ampara em funções simbólicas. E quando enunciamos o que da mãe se impõe na relação com seu filho, o que destacamos é que, mais do que a mulher como sujeito, estamos falando de uma mãe enquanto função.

A formalização edípica nos remete à estrutura da linguagem enquanto organizadora das funções parentais exercidas não somente por quem almeja o lugar de pai ou mãe, mas por qualquer pessoa que porventura possa ocupar esse lugar. Ancorado no campo da linguagem, o Outro, em um primeiro momento, também denominado de Outro primordial, é incorporado pela figura da mãe. É necessário, mais uma vez, destacarmos que, em psicanálise, o que está em jogo não é a mãe real, que expressa seus sentimentos, cuidados e devoções pelo filho, mas sim a mãe que faz parte de uma estrutura, que se revela como função e que se apresenta na ordem de uma transmissão.

Tratar a constituição do sujeito pelo édipo "como se tudo começasse pela mãe faz com que tendamos ao evolucionismo ... não há uma mãe primeira, posteriormente um pai e finalmente uma criança; o que há é um sujeito que se constitui a partir de uma metáfora" (Vieira, 2015, p. 19). Nessa perspectiva, Lacan (1969/2003) discursa sobre a combinação da função materna e da função paterna, que estariam incumbidas de realizar a travessia do bebê enquanto sujeito. Essas funções não tratam da figura de uma mulher e de um homem, mas de sujeitos que exercem uma função, que está para além da simples satisfação das necessidades do bebê.

Assim, a posição materna, a qual nos interessa e é cara à psicanálise, se refere à posição da mãe, que, ao exercer sua função, é impulsionada por um desejo de modo a antecipar ao seu bebê uma subjetividade, ainda não presente, mas já suposta. Por meio da linguagem e de seu olhar, ela investe libidinalmente no corpo do filho, que, de organismo, passa a ser um corpo erógeno, um corpo marcado pelo significante (Kupfer, 2000).

Além disso, essa função se efetiva quando existem um saber e um não saber a respeito da criança, uma presença e uma ausência do lado da mãe, permitindo que outros possam responder a respeito dela, e não somente a mãe. O olhar da função materna e a forma como esta faz laço com seu filho são fundamentais para que ele seja subjetivado, constitua sua imagem corporal e, consequentemente, possa fazer um laço com o Outro (Teperman, 1999). Em outros termos, Lacan (1969/2003) situa como sendo de responsabilidade da função materna a transmissão de um desejo ao bebê que não se configure como anônimo, ou seja, que remeta a um desejo e uma significação pela existência de seu filho; em outras palavras, que dê nome ao lugar que a criança ocupa para a mãe, uma vez que o filho necessita do laço materno que se apresenta pelo olhar e pelo desejo da mãe para sua subjetivação.

Por outro lado, conforme Bruno (1999), o desejo que se apresenta como anônimo se mantém sem nenhuma nomeação; isto é, nada conseguiu dar nome ao lugar que a criança ocupa para a 
mãe. O próprio desejo da mãe não pode ser ratificado por ela, não foi possível subjetivá-lo; ou melhor, é preciso reconhecermos esse desejo enquanto simbólico. Todavia, cabe ressaltarmos que existe um desejo, ainda que sem nome, pois, se ele fosse inexistente, o filho gerado não sobreviveria (Bruno, 1999 citado por Abramovitch \& Castro, 2014).

A função materna como primeiro objeto de amor e de troca estabelecida com a criança revela a possibilidade de um desejo que vivifica o filho em uma posição separada da mãe. Para isso, como nos diz Lacan (1969/2003), há a presença de um terceiro, o pai, e sua função, que permite que essa posição se localize como separada da mãe.

A entrada do pai como uma função avança, sobremaneira, sobre o que pensavam os pósfreudianos, os quais depositavam excessiva ênfase na relação da mãe com o filho. A função paterna é mediadora da relação entre mãe e filho, uma vez que deverá haver sempre um terceiro. Nessa relação, o falo se revela como referência a um terceiro elemento para o qual o desejo da mãe deve se dirigir. É o que nos aponta Lacan (1957-1958/1999) ao dizer sobre a função constitutiva do falo, como impossível de deduzir, na dialética de entrada do sujeito em sua existência, "se não fizermos dele o significante fundamental pela qual o desejo do sujeito tem que se fazer reconhecer como tal" (p. 285). E o fato, continua Lacan (1957-1958/1999), é que o desejo, seja ele qual for, tem no sujeito essa referência fálica. A mediação paterna, na relação entre mãe e criança, portanto, é primordial para a ascensão desta à posição de sujeito, pois ela sempre se revela intermediada pela função fálica, o que dificulta a relação intensa entre elas.

Desse modo, em detrimento de uma relação ancorada na maternagem que se revelou durante muito tempo como primordial na vida de um sujeito, no que concerne à constituição subjetiva, pai e mãe se apresentam como função que permite que o sujeito apareça singularmente e se coloque em um lugar particularizado referenciado pelo nome do pai como função primordial.

\section{Mulher Mãe: de santificada a devastadora}

É fundamental a compreensão de que, por muito tempo, a feminilidade de uma mulher apoiou seu discurso em função da maternidade. Dessa maneira, foi instituída à mulher a missão de ser mãe, incorporada pela crença do existir de um amor materno incondicional direcionado aos seus filhos. Esse amor, descendente de um "instinto materno", por sua vez, é inato e característico da própria natureza humana (Badinter, 1980/1985, p. 21). Contudo, até o final do século XVIII, os laços entre mãe e filho eram ancorados por certa indiferença materna. $\mathrm{O}$ filho, desde seu nascimento, costumava ser confiado a uma ama-de-leite, responsável por sua alimentação e demais cuidados, posteriormente, a uma governanta e, então, ao internato (Badinter, 1980/1985).

A indiferença materna referida, analisada, muitas vezes, como frieza, insensibilidade, pode ser justificada pela ordem econômica, social e moral que regia aquela época. E, além disso, a alta taxa de mortalidade infantil imputava indiretamente em grande parte das mães um sentimento de não se apegar às suas crianças, visto que poderiam perdê-las (Badinter, 1980/1985). No entanto, para além das necessidades de ordem econômica e social que porventura possam macular a relação entre mãe e filho, há, na ausência do laço entre mãe e filho, um ponto nevrálgico que se impõe considerar.

Segundo Kehl (2008), as mulheres dos séculos XVIII e XIX eram determinadas por sua feminilidade, que se expressava por uma variedade de atributos pessoais, os quais incluíam a própria anatomia corporal e a capacidade de gerar um filho, de modo que a feminilidade de 
uma mulher se fez serva da maternidade. Assim, as mulheres passaram a se encobrir de características próprias do feminino, tais como: "o recato, a docilidade, uma receptividade passiva em relação aos desejos e necessidade dos homens" (Kehl, 2008, p. 48), para corresponder às expectativas de outrem. Ainda, cabe ressaltarmos, diz-nos Badinter (1980/1985), que, por muito tempo, houve uma identificação da mulher com a Virgem Maria, retrato do amor e da pureza, cuja identificação aproximava sua referência da feminilidade, maternidade e até mesmo santidade.

Freud (1932/1976), quando tratou da questão do feminino, considerou que um dos destinos da feminilidade era a maternidade de forma que a mulher alcançaria seu lado feminino com o desejo de ter um filho e, posteriormente, com o nascimento deste. Posição que aponta a mulher como nostálgica do falo o que incorreria na busca metafórica de um encontro com o falo ao se ter um filho e tornar-se mãe. Lacan (1972/2003), por outro lado, produziu, de forma bem clara, a separação entre mãe e mulher, elaborando, a partir de então, a perspectiva de uma posição materna, bem distante do que acreditam aqueles que, porventura, ainda confundem com a mãe em "carne e osso". Ambos engendraram uma forma de escuta que reconhece, pela linguagem, o que do enunciado sobre o materno surge sobre a posição materna.

Segundo Alvarenga (2015), o que se vincula ao tema mãe se mostra pluralizado, essencialmente pelas variadas formas de se produzir uma mãe: mãe biológica, mãe de aluguel, adotiva. Entretanto, mais do que se prender a rótulos que poderiam dizer dessa mãe, o tema sobre a mãe sempre se sustentou em sua posição no campo da linguagem e do desejo em relação ao filho. Ou seja, para além do campo biológico, que assegura que determinada mulher é mãe, esse fato não garante o exercício da função materna.

Nessa posição mencionada, a maternidade é uma cena marcada pela imprevisibilidade e pela falta de garantias de como será o exercício de uma posição que remete ao desejo de cada um pelo filho. Na relação mãe e filho, Freud (1931/1980) revela um modelo em que, de um lado, há uma mãe como objeto de satisfação primária e, de outro, um pai com uma função de limitação e proibição.

Depois "desse pai do mito de Édipo, foi a mãe que os pós-freudianos conduziram ao palco das causas", afirma Soler $(2003 / 2005$, p. 88). Os pós-freudianos, como Melanie Klein (1965/1981), Winnicott (1971/1975) e Badinter (1980/1985), por exemplo, compartilham das ideias freudianas a respeito dessa relação mãe-criança, em que existiria uma harmonia nessa relação. Expressaram, ainda, que a criança está em desenvolvimento e se coloca como um "objeto parcial", que busca interagir com um "objeto adequado e harmonioso", de modo que essa mãe deve se apresentar como tal, adequada e harmoniosa (Farias \& Lima, 2004, p.18). Portanto, na orientação pós-freudiana, adeptos da relação de objeto se dirigem à relação mãe e filho como dual, em desenvolvimento, cuja direção visa a uma completude com a mãe.

No que concerne à orientação lacaniana, esta retifica o desvio realizado pelos pósfreudianos em relação à criança enquanto complemento libidinal materno em busca de uma complementaridade, mas revela a criança como um sujeito dividido, fazendo parte de uma estrutura do Outro como um objeto separado desse Outro. Do mesmo modo, em relação ao édipo freudiano e aos complexos de Édipo e de castração, Lacan (1969-1970/1992) avança em um para além do Édipo em que o desejo da mãe se apresenta como pano de fundo na relação com a criança.

Lacan (1969-1970/1992) marcou a importância do desejo da mãe, o que convoca a um olhar não para o amor da mãe, mas para o desejo da mulher. Um desejo que traz a marca de uma mulher barrada, Outra. Do amor materno ao desejo materno, o que o desejo da mãe vem 
apresentar é algo da ordem da falta fundamental. O desejo da mãe vem nomear o desejo da mulher na mãe, o que permite a essa mãe ser não toda para seu filho, pois seu olhar se localiza em outra direção que não seja somente ele.

Lacan, no "Seminário, Livro 17: O avesso da psicanálise" (1969-1970/1992), nomeia o desejo como devastação, no que ele se apresenta como excessivo, e completa: "O desejo da mãe não é algo que se possa suportar assim, que lhes seja indiferente. Carreia sempre estragos" (p. 118). O tema da devastação retorna em 1973 em "O Aturdido", quando Lacan marca o contraste em relação a Freud ao afirmar que a castração "faz da mulher peixe na água, pela castração ser nela ponto de partida" (p. 465). E por fim em "O Seminário, Livro 23: O sinthoma" (1975-1976/2007), no qual Lacan faz referência à devastação nas relações amorosas. Desse modo, nessas três passagens de Lacan pelo termo devastação, notamos que o primeiro se refere ao desejo da mãe sobre os filhos, sejam estes meninos ou meninas; o segundo se refere à relação entre a mãe e a filha; e, no terceiro, a devastação se apresenta na relação amorosa entre o homem e a mulher.

Contemporâneo à primeira passagem, em que Lacan se refere ao desejo da mãe sobre os filhos, no texto "Nota sobre a Criança", Lacan (1969/2003) propõe que tal relação é, sobretudo, marcada pela falta; logo, não há completude possível: “da mãe, na medida em que seus cuidados trazem a marca de um interesse particularizado, nem que seja por intermédio de suas próprias faltas" (p. 369). Lacan, nesse texto, define a mãe não só como aquela tão comumente retratada no lugar dos primeiros cuidados e no campo das necessidades básicas do bebê, mas sim uma mãe marcada pela falta, pela castração, o que rompe com a solução de completude. No entanto, esta mãe faltosa em seus cuidados poderá significantizar esse filho, marcando-o com um interesse particularizado. Isso não quer dizer que se está preocupado com o fato de ser uma boa mãe ou má mãe, mas que esta apresente um interesse particularizado pelo filho. O que isso quer dizer? Uma coisa é dizer eu amo todas essas crianças e outra é dizer que amo uma criança por algo que ela tenha e amo a outra por outra coisa que ela tenha (Vieira, 2005). A função materna se transmite, então, por um cuidado da mãe, mas que este seja particularizado na criança, com cada criança e sua mãe.

Em comunhão com tal proposição lacaniana, Jerusalinsky (2014) conclui que não há naturalidade na relação maternante com seu filho, tampouco simetria. O que se observa é uma relação de faltas entre eles. Sugere, pois, ainda, que, em meio a essa incompletude, o que se torna viável é o estabelecimento de um laço; em outras palavras, a maternidade decorre do estabelecimento de um laço simbólico da mãe com seu bebê. Assim, podemos perceber que Lacan desmistifica a ideia de que a feminilidade de uma mulher pode ser justificada ou resumida pela maternidade. Expressão disso reside na própria sociedade atual, na qual se assiste a uma "diversificação em seus modos de acesso à realização fálica, fazendo da maternidade uma escolha possível entre tantas outras" (Jerusalinsky, 2014, pp. 20-21). A experiência da maternidade é uma experiência em que a mãe se vê confrontada com a castração enquanto falta diante do filho ou do parceiro, ou com aquilo que do feminino não pode ser recoberto pela maternidade (Alvarenga, 2015, p. 9). Desse modo, de santificada a devastadora, o que nos esclarece é que a nomeação do filho como um desejo que não seja anônimo se coloca como fundamental no exercício dessa função. 


\section{Relação mãe-criança, criança-mãe}

Retomemos, então, a problemática já exposta no início deste trabalho, no qual se trata da posição em que se encontra a mãe do sujeito autista na relação subjetiva que ela tem com seu filho. A partir da leitura de diferentes autores, observamos a defesa de alguns pontos de vista que se convergem e outros que se divergem a respeito dessa posição.

Laznik Penot (2013) trata o autismo como um "fracasso no tempo da própria alienação", na qual não se verifica o olhar entre a mãe e seu filho, como também não se verifica o fechamento do circuito pulsional na criança. A autora acredita, ainda, que o autismo seja decorrente de uma falha na formação do laço mãe e criança, pois é a partir de tal que o sujeito do inconsciente poderá se constituir. Chama-nos atenção a posição de Laznik Penot (2013) ao demarcar um posicionamento não só da mãe, mas também da própria criança em que a não resposta da criança pode desorganizar sua mãe.

De forma análoga a Laznik Penot, essencialmente no que concerne a uma não resposta da criança à mãe, Kupfer (2000) propõe a existência de uma "falha da função materna" (p. 91) no autismo, tendo em vista que, algumas vezes, a mãe até a colocou em exercício, mas foi a criança que não conseguiu absorvê-la. Assim, ela considera que, a partir dessa falência, o autismo pode se apresentar diante da "inoperância radical da função e do desejo materno" (p. 91), tendo como consequência a não presença da imagem corporal pela criança, ou, ainda, resultar em uma dificuldade na relação especular com o Outro, e, então, vir a apresentar alguns traços característicos do autismo, porém associados a outras patologias.

Telles (2012, p. 74), por sua vez, em concordância com alguns autores psicanalistas, referese ao autismo como um reflexo de algo que afetou o desejo materno de tal forma que prejudicou seu investimento libidinal no corpo de seu filho. Dessa maneira, no autismo, a falta da inscrição significante, por parte do Outro primordial, não produz na criança a delimitação de seu corpo sob bordas erógenas.

É preciso ressaltarmos, ainda, outras observações de Telles (2012) após analisar o discurso de mães de autistas a respeito do primeiro olhar, para com seus filhos. A autora percebeu que essas mães trazem, em comum, uma "insuficiência do papel materno" (p. 80) de modo que a utilização do recurso simbólico, por parte da mãe em conceder significantes à sua criança, é afetada por adversidades, dores e decepções. Tais mães foram acometidas por diversas situações no nascimento de seus filhos, que trouxeram dificuldades e até mesmo o impedimento em estabelecer um vínculo harmonioso com seu filho, de maneira que o exercer de sua função se tornou prejudicado.

Teperman (1999) ressalta, ainda, que o nascimento da criança marca um limite à fantasia dos pais, uma vez que há sempre um desencontro, um mal-entendido, uma diferença entre o filho que é esperado e o filho que nasce. De certo modo, esse desencontro se configura como saudável de maneira a propiciar à criança se mostrar como única, com características próprias, que deverão ser significadas por seus pais. Por outro lado, diz-nos Teperman (1999), essa diferença pode tomar uma proporção ainda maior, cuja simbolização da criança por seus pais se torna inviável, em que o nascimento pode assumir um caráter de desorganização, que impõe obstáculos no desejo da mãe de tal forma que ela fica impossibilitada de cumprir com sua função materna e supor um sujeito em seu filho que nasceu, mas que não era "aquele" que ela esperava.

Reiterando a não resposta da criança à função materna, Coriat (1997, p. 9), ao ouvir os pais de algumas crianças tidas como autistas, notou que seu autismo já vinha sido provocado desde 
uma história precedente, como se estivesse "modelando no real o objeto fantasmático" do casal parental; logo, a criança autista seria a realização de um fantasma materno. Por outro lado, ouvindo outros pais dessas crianças, fica claro para essa autora que não há razão suficiente em seus discursos para que seus filhos sejam autistas, o que leva a pensar que existe, também, uma parcela de implicação do próprio sujeito, uma escolha. Coriat (1997) remete, então, a uma metáfora, na qual compara a criança como um papel e a mãe como a mão que vai escrever no papel dizendo que em geral se esquece do papel ao se preocupar com as palavras que queremos imprimir nele, mas "passamos a levá-lo em conta quando alguma das características materiais do papel dificultam que as letras sejam escritas com clareza" (p. 11).

Assim, quando a função materna não consegue libidinizar a criança e inscrevê-la num campo simbólico, nos seus primeiros momentos de vida, poderá acarretar desencontros e efeitos em sua constituição subjetiva. Todavia, esses desencontros podem vir não só do lado da mãe, mas do bebê também.

Comungando da mesma ideia, é interessante notarmos, em um trabalho feito por Campanário (2008), que tais dificuldades existentes no estabelecimento do laço da mãe com seu bebê autista não manifestavam, em alguns casos, na função desempenhada pelo agente maternante, mas nas próprias respostas de recusa da criança do que era ofertado por sua genitora, o que denota, mais uma vez, um posicionamento de mão dupla: por parte da mãe e também da criança.

\section{Considerações finais}

A ideia da "mãe geladeira" trouxe em seu âmago um equívoco considerável diante dos efeitos que apresentou nas pesquisas sobre a constituição subjetiva dos sujeitos, tendo em vista que muitas patologias da infância, inclusive o autismo, tiveram sua base etiológica coladas na concepção materna adotada por tal teoria.

Portanto, esta causalidade do autismo ancorada na perspectiva materna não é o foco de nossas pesquisas psicanalíticas. Muito pelo contrário. O intento sempre será desculpabilizar essas mães acerca da condição de seus filhos, investigando o que estaria latente nesta relação mãe e filho, o que estaria submerso como respondendo à ordem inconsciente. Pois é desta ordem que tratamos: do inconsciente como estrutura e das funções inerentes do pai e da mãe representados nessa estrutura.

No que se refere às patologias da infância em que a mãe foi colocada como atriz principal da cena, a história da psicanálise nos mostra que os sintomas e seus efeitos não são totalmente sujeitos à decifração, pois há sempre algo que escapa a esta e que se apresenta como um ponto estrutural no psiquismo do sujeito. O sintoma é uma patologia de estrutura, afirma-nos Miller (1998), e ele se apresenta como um efeito, atestando certa fissura no psiquismo que escapa à decifração. No entanto, diz-nos Soler (2003/2005), a possibilidade de um equívoco se fez ao imputar à manifestação do sintoma uma distorção da ordem do individual e à mãe, que, por sua vez, encarnava o primeiro objeto do gozo impossível. Além do mais, a fala dos analisandos coloca recorrentemente a mãe como inscrita em suas lembranças mais marcantes, o que pode ter incorrido em uma distorção da posição da mãe nessa relação. Atribuir à mãe ou à família algo de uma falha, um erro, no que se refere à constituição subjetiva do sujeito, não é isso o pressuposto da psicanálise. Soler (2003/2005) continua

Muitas coisas transitam entre as gerações sem dúvida, mas, com certeza, não a causa dos sintomas: invocar uma causalidade familiar nesse nível tornaria ininteligíveis os efeitos 
terapêuticos da fala sob transferência, que se desenrola totalmente no espaço do sujeito. Mas isso não impede que cada um traga no mais íntimo de si a marca do 'Outro primordial' (p. 89).

Compreendemos que o laço que se estabelece entre mãe e filho é permeado por aspectos inconscientes dos próprios pais da criança e, que, além disso, a dificuldade existente nessa relação advém de dificuldades que se originaram na relação primária desses pais com seus próprios pais e que se tornam vivos com o nascimento da criança. Esta, por sua vez, apresenta um papel de "curador", pois permite que eles recriem e elaborem relacionamentos mal resolvidos no passado e construam novo relacionamento entre a tríade (Albornoz, 2006).

Contudo, há de se convir que muitos dos autores estudados revelam que há um posicionamento que é da própria criança enquanto sujeito, que pode facilitar ou dificultar o estabelecimento de um laço com seu Outro materno. Como vimos, esse laço demanda uma construção, sendo ele perpassado pelos próprios cuidados maternos endereçados ao bebê e revestidos pelo investimento libidinal e pela oferta de significantes ao bebê, que, paulatinamente, ganham correspondência nele (Jerusalinsk, 2014).

Assim, podemos situar e concluir que a função materna é uma posição estrutural que se referencia como primeiro objeto de amor e de troca estabelecida com a criança, peça fundamental em sua constituição subjetiva, mas não é a única, visto que há uma posição advinda da própria criança enquanto sujeito a respeito de sua condição seja ela no autismo ou em outras patologias infantis. Desse modo, questionamos: a culpa é de quem? Não há culpados aqui. Seja a mãe, seja a criança, ambas sustentam uma posição singular, enquanto sujeitos, que fazem parte de uma estrutura e demandam por uma invenção e construção acerca de si mesmas. Não há culpabilização nessa relação, mas sim responsabilização de como cada sujeito responde de sua posição subjetiva.

A expressão proferida pelo pai de uma criança autista à mãe, apontada no início deste artigo, ratifica o equívoco recorrente em apontarmos a "teoria da mãe geladeira" como representando a práxis psicanalítica. Isso nos faz pensar que esse é mais um dos ataques à psicanálise como tentativa de exclusão desta no tratamento de crianças.

\section{Referências}

Abramovitch, S., \& Castro, S. (2014). Autismo: desejo paradoxal. Heteridade, Rev. de Psicanálise, $\quad 11(1), \quad 108-115 . \quad$ Disponível https://www.champlacanien.net/public/docu/4/heterite11.pdf

Albornoz, A. C. G. (2006). Fantasmas no berço e o psiquismo do bebê. Revista Barbarói da Universidade de Santa Cruz do Sul, 2(25), 155163.doi: http://dx.doi.org/10.17058/barbaroi.v0i0.735

Alvarenga, E. (2015). Apresentação do livro. In C. Alberti, Ser mãe: mulheres psicanalistas falam da maternidade (pp. 5-13). Belo Horizonte, MG: EBP.

Badinter, E. (1985). Um amor conquistado: o mito do amor materno (M. L. X. de A. Borges, trad.). Rio de Janeiro, RJ: Nova Fronteira. (Trabalho original publicado em 1980).

Barroso, S. F. (2014). As psicoses na infância: o corpo sem a ajuda de um discurso estabelecido. Belo Horizonte, MG: Scriptum Livros. 
Bettelheim, B. (1987). A fortaleza vazia. São Paulo, SP: Martins Fontes. (Trabalho original publicado em 1967).

Bruno, P. (1999). O dito - sobre a esquizofrenia. In S. Alberti (Org.), Autismo e esquizofrenia na clínica da esquize (pp. 177-196). Rio de Janeiro, RJ: Rios Ambiciosos.

Campanário, I. S. (2008). Espelho, espelho meu: a psicanálise e o tratamento precoce do autismo e outras psicopatologias. Salvador, BA: Ágalma.

Coriat, E. (1997). Causas e acasos. Estilos da Clínica, 2(3), 814.doi: https://doi.org/10.11606/issn.1981-1624.v2i3p8-14

Eulálio, A. (2018). Amores loucos: a devastação materna e nas parcerias amorosas. Belo Horizonte, MG: Artesã.

Farias, C. N. F., \& Lima, G. G. (2004). A relação mãe-criança: esboço de um percurso na teoria psicanalítica. Estilos da Clínica, 9(16), 12-27. doi: https://doi.org/10.11606/issn.19811624.v9i16p12-27

Freud, S. (1980). A sexualidade feminina. In S. Freud, Edição standard brasileira das obras completas de Sigmund Freud (J. Salomão, trad., Vol. 21, pp. 135-150). Rio de Janeiro, RJ: Imago. (Trabalho original publicado em 1931).

Freud, S. (1980). Feminilidade. In S. Freud, Edição standard brasileira das obras completas de Sigmund Freud (J. Salomão, trad., Vol. 22, pp. 75-92). Rio de Janeiro, RJ: Imago. (Trabalho original publicado em 1932).

Jerusalinsky, J. (2014). A criação da criança: brincar, gozo e fala entre a mãe e o bebê. Salvador, BA: Ágalma.

Kanner, L. (1997). Os distúrbios autísticos do contato afetivo. In P. S. Rocha et al. Autismos (M. Seincman, trad., pp. 111-170). Recife: Escuta. (Trabalho original publicado em 1943).

Kehl, M. R. (2008). Deslocamentos do feminino (2a ed.). Rio de Janeiro: Imago.

Kupfer, M. C. M. (2000). Notas sobre o diagnóstico diferencial da psicose e do autismo na infância. Psicol. USP, 11(1), 85-105. doi: http://dx.doi.org/10.1590/S010365642000000100006.

Klein, M. (1981). Contribuições à psicanálise (M. Maillet, trad.). São Paulo: Mestre Jou. (Trabalho traduzido diretamente da terceira edição em inglês).

Lacan, J. (1992). O seminário, livro 17: o avesso da psicanálise (A. Roitman, trad., A. Quinet, consult.). Rio de Janeiro, RJ: Jorge Zahar. (Trabalho original publicado em 1969-1970).

Lacan, J. (1999). O seminário: livro 5: as formações do inconsciente (V. Ribeiro, trad., M. A. Vieira, rev.). Rio de Janeiro, RJ: Jorge Zahar. (Trabalho original publicado em 1957-1958).

Lacan, J. (2003). Nota sobre a criança. In J. Lacan, Outros escritos (V. Ribeiro, trad., pp. 369370). Rio de Janeiro, RJ: Jorge Zahar. (Trabalho original publicado em 1969).

Lacan, J. (2003). O aturdido. In J. Lacan, Outros escritos (V. Ribeiro, trad., pp. 448- 497). Rio de Janeiro, RJ: Jorge Zahar (Trabalho original publicado em 1972).

Lacan, J. (2007). O seminário, livro 23: o sinthoma (S. Laia, trad., A. Telles, rev.). Rio de Janeiro, RJ: Jorge Zahar (Trabalho original publicado em 1975-1976).

Laznik Penot, M.-C. (2013). A voz da sereia: o autismo e os impasses na constituição do sujeito. Salvador, BA: Ágalma. 
Lefort, R., \& Lefort, R. (1991). Unidade da psicanálise. In J. Miller, A criança no discurso analítico (D. D. Estrada, trad., pp. 11-12). Rio de Janeiro, RJ: Zahar. (Trabalho original publicado em 1983-1988).

Lefort, R., \& Lefort, R. (1991). Introdução à Jornada de Estudos do CEREDA. In J. Miller, A criança no discurso analítico (D. D. Estrada, trad., pp. 13-14). Rio de Janeiro, RJ: Zahar. (Trabalho original publicado em 1983-1988).

Lobo, S. (2008). As condições de surgimento da "Mãe Suficientemente Boa". Revista Brasileira de Psicanálise, 42(4), 67-74.

Lopes, B. (2017). Autismo e culpabilização das mães: uma leitura de Leo Kanner e Bruno Bettelheim (pp. 1-10). Florianópolis: Seminário Internacional Fazendo Gênero $11^{\text {th }} \& 13^{\text {th }}$ Women' Worlds Congress (Anais Eletrônicos).

Miller, J. A. (1998). O osso de uma análise [Seminário proferido no VIII Encontro Brasileiro do Campo Freudiano e no II Congresso da Escola Brasileira de Psicanálise. Salvador - Bahia - 17 a 21 de abril de 1998. J. Gerbase, rev. téc.]. Revista da Escola Brasileira de Psicanálise.

Ribeiro, J. M. C. (2013). A criança autista em trabalho (2a ed.). Rio de Janeiro, RJ: 7 Letras.

Soler, C. (2005). O que Lacan dizia das mulheres (V. Ribeiro, trad., M. A. C. Jorge, consult.). Rio de Janeiro, RJ: Jorge Zahar. (Trabalho original publicado em 2003).

Telles, C. M. A. (2012). A escuta discursiva de mães de crianças autistas: o primeiro olhar sobre o filho. Cad. Psicanál., 34(26), 67-83.

Tustin, F. (1975). Autismo e psicose infantil. (I. Casson, trad.). Rio de Janeiro, RJ: Imago. (Trabalho original publicado em 1972).

Teperman, D. W. (1999). Do desejo dos pais ao sujeito do desejo. Estilos da Clínica, 4(7), 151158.doi: https://doi.org/10.11606/issn.1981-1624.v4i7p151-158

Vasconcelos, A. (s.d.). Autismo e psicose infantil exílio e prisão de uma relação imaginária? Disponível

em http://www.portcom.intercom.org.br/pdfs/b0ecef7f41ce906080dfc4413953d30c.PDF

Vieira, M. A. (2005). Nota sobre a criança, de Jacques Lacan: uma leitura. [Versão do texto de duas aulas ministradas no curso organizado por Silas Nascimento].

Winnicott. D. W. (1975). O brincar e a realidade (J. O. de A. Abreu \& V. Nobre, trad.). Rio de Janeiro, RJ: Imago. (Trabalho original publicado em 1971). 